\title{
http:// bjas.bu.edu.eg \\ Shark Liver Oil Protects the Chromosome and Sperm of Mice against the \\ Cytotoxicity of Taxotere
}

M.Zowail, M. M.Refaat, M.H.Awwad, E.Khater, and E.H.O.Nafie

Zoology Dept., Faculty of Science, Benha Univ., Benha, Egypt

E-Mail: Marwa.Refaat@fsc.bu.edu.eg

\begin{abstract}
The natural ether-lipids 1-O-alkylglycerols from shark liver oil (SLO) supposed to improve sperm motility and fertility. Also, they reduce the side effects of radiotherapy, inhibit tumor growth and both stimulate and modulate immune responses. This study aimed to show the protective effect of SLO against the side effects of Taxotere on mice chromosomes and sperms. Thirty adult male mice weight $(23-27 \mathrm{gm})$ were used in this study. The animals were housed in plastic cages at the same temperature and humidity conditions. They were divided into 6 groups each one contains 5 male mice that were used for studying chromosomal abnormalities and sperm head and tail morphology by using classical cytogenetic methods. The administered doses of Taxotere were $8 \mathrm{mg} / \mathrm{kg}$. Mice injected SLO at a dose of $(10 \mathrm{mg} / \mathrm{kg} /$ day $)$. Results showed that Taxotere caused structural and numerical chromosomal aberration including deletion, centromeric attenuation, ring, monoploidy, and polyploid. It also caused sperm head and tail abnormalities such as without hook, amorphous, hummer head and sperm with a coiled tail. Our results proved the efficiency of SLO to protect mice chromosomes and sperms against the cytotoxic effect of Taxotere.
\end{abstract}

Keywords: Shark liver oil, Taxotere, Chromosomal aberrations, Sperm abnormalities.

\section{Introduction}

Taxotere (Docetaxel) is a second-generation taxane extracted from the needles of the European yew tree [1]. Taxotere is an agent with significant clinical antitumor activity like ovarian, breast, and prostate cancers. Its activity has also been seen in a number of tumors that are generally refractory to other chemotherapeutic agents, such as lung, head and neck, bladder, and esophageal cancers, as well as in metastatic breast and lung cancers [2].

Each vial of Taxotere Injection Concentrate is a sterile, non-pyrogenic, pale yellow to the brownish-yellow solution at $20 \mathrm{mg} / \mathrm{mL}$ concentration. Each $\mathrm{mL}$ of 1-vial Taxotere contains $20 \mathrm{mg}$ Docetaxel in 0.54 grams polysorbate 80 and 0.395 grams dehydrated alcohol solution[3].

Taxotere binds to $\beta$-tubulin subunits that prevent microtubules depolymerizing causing disruption in mitotic spindle formation results in inhibition of cell division and lead to cell death [4]. An additional mechanism of action of Taxotere may be phosphorylation of members of the BCL2 family of proteins [5]. Taxotere has been shown to inhibit angiogenesis both in vitro and in vivo[6].

Shark liver oil (SLO) is obtained from the fresh and livers of various species of sharks.

SLO reduces the side effects of radiotherapy, inhibits tumor growth and both stimulate and modulate immune responses [8]. Many different mechanisms are suggested for these multiple activities, resulting from the incorporation of alkylGro into membrane phospholipids, and lipid signaling interactions[9].

\section{Material and methods}

\subsection{Experimental design}

Thirty adult male mice weight $(23-27 \mathrm{gm})$ that were used in this study. The animals were housed in cages at the same conditions from temperature and humidity. The experimental animals were categorized into 6 groups, each included 5 animals. The animal received various treatments for different periods as shown in Table (1).

\subsection{Taxotere (Docetaxel)}

The mice have injected IP with Taxotere. The administered doses of Taxotere were $8 \mathrm{mg} / \mathrm{kg}$ by [10].

\subsection{Shark liver oil (SLO)}

We get SLO capsule from El - Ezabi pharmacy. Each contains 100\% pure natural arctic extracted from the liver of the Shark. Mice injected a dose of SLO (10 mg/kg/day) [11].

\subsection{Chromosomal preparation experiment}

After the last day of injection animals were sacrificed. Bone marrow cells collected from mice femurs for mitotic index and chromosomal aberration studies. According to [12].

\subsection{Sperm morphology assay}

The epididymis of each mouse was taken and minced carefully with scissors in saline solution for obtaining sperms then the solution was filtrated to get rid of large debris of tissues. The solution with sperms was stained by $1 \%$ eosin [13] then were 
spread on clean sild and were examined under a light microscope.1000 sperm per mice were examined for head and tail morphology abnormalities detection.

Table(1)

Group treatment:-

Group (1):- Control group- 5 mice with no injection.

Group (2):- Taxotere group- 5 mice have injected IP with Taxotere three times per week for two weeks.

Group (3):- Natural product group-5 mice have injected IP with shark liver oil every day for two weeks.

Group (4):- 5 mice were injected with Taxotere for two weeks then with shark liver oil also for two weeks. (Taxotere+SLO).

Group (5):- 5 mice were injected with shark liver oil for two weeks then with Taxotere also for two weeks. (SLO+Taxotere).

Group (6):- 5 mice were injected with Taxotere and shark liver oil at the same time. (Taxotere\&SLO).

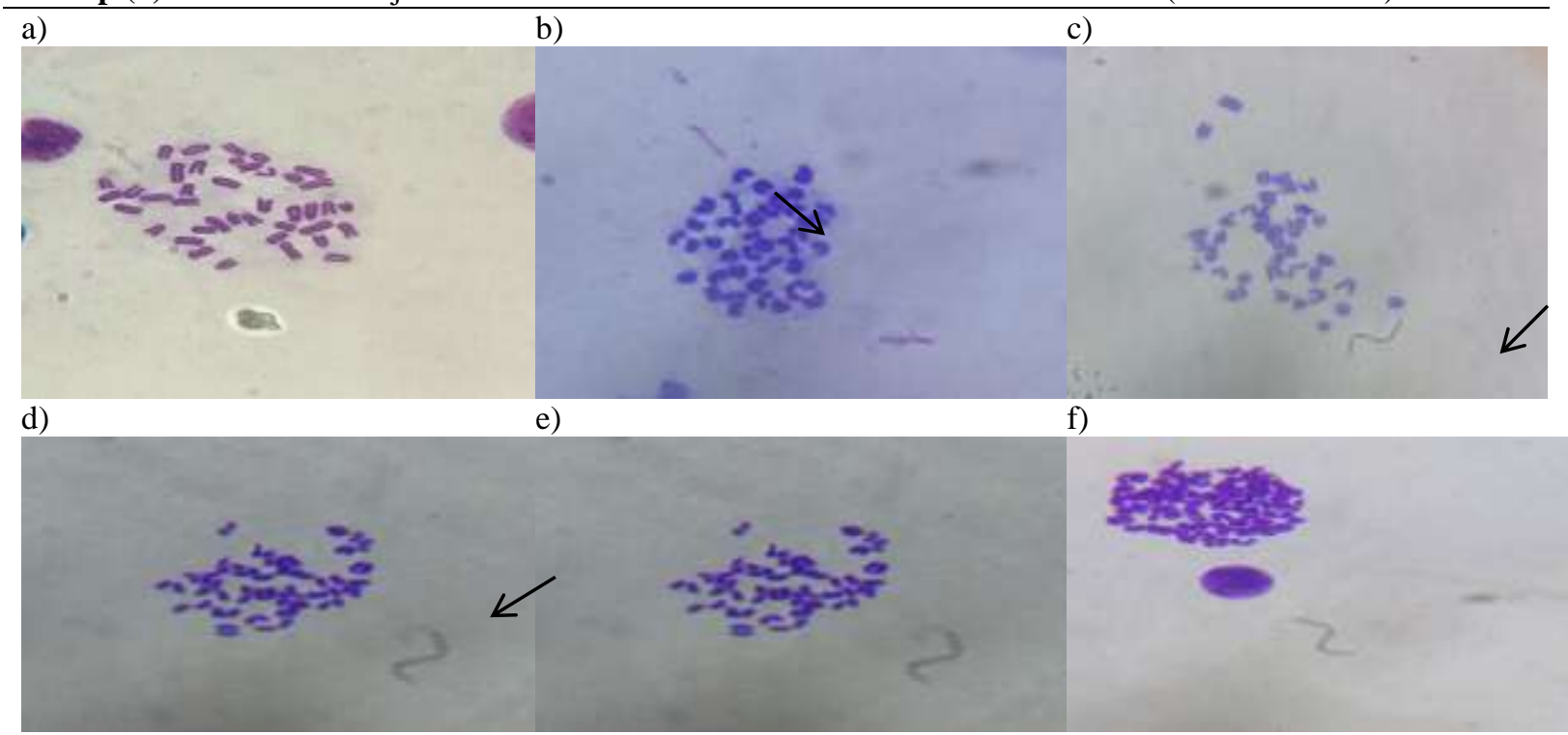

Fig(1) A) normal chromosome. B) Deletion. C) centromeric attenuation. D) ring. E) monoploid. F) polyploidy.

\section{Statistical analysis}

It was performed by using SPSS software (version 14) and by using a T-test. When $\mathrm{P}$ value less than 0.05 it was considered as a significant value also mean and standard error was calculated [14].

\section{Results and discussion}

There are two types of chromosomal aberration; structural and numerical chromosomal aberration and both of them were detected in 50 metaphases well-spread fields per mice. The normal sample in Fig. (1a) shows that mice contain 20 pair of chromosomes. Chromsomal abnormalities represented as deletion Fig. (1b), centromeric attenuation Fig. (1c), ring fig. (1d), momoploid fig. (1e), polyploidy Fig (1f).

The mean values of total chromosomal aberration in mice were represented in table (2) and Fig. (2). These data show that there was no significant difference between the control group and the Shark liver oil (SLO) treated group as the mean values were $((5.4 \pm 2.1)$ and $(7.8 \pm 2.31))$.

There was also a significant increase in the mean values of the Taxotere treated group over the mean value of the control group and SLO only treated group where the mean values of them were $((174.6 \pm 9.63)$ vs(5.4 \pm 2.1$)$ and $(7.8 \pm 2.31))$.

Using SLO as a treatment after Taxotere dose injection showing a significant decrease in total chromosomal aberration comparing with taxotere only treated group with mean values were $((84.6 \pm 4.41) v s \quad(174.6 \pm 9.63))$. Also, the protective effect of SLO injection before Taxotere treatment showing a significant decrease in total chromosomal aberration comparing with taxotere only treated group as the mean values were $(136.4 \pm 6.61) v s(174.6 \pm 9.63))$. The injection of Taxotere at the same time with Slo also showing a significant decrease in total chromosomal aberration comparing with taxotere only treated group as the mean values were $((102.6 \pm 6.18)$ vs 
(174.6 \pm 9.63$)$ All these results show that using Slo as a treatment after Taxotere treatment was more effcient than the protective effect of Slo and than the injection of both SLO and Taxotere at the same time in decreasing the total chromosomal abberation caused by Taxotere treatment.

The mean values of total sperm abnormalites in mice were represented in Table (3) and Fig. (3). These data show that there was no significant difference between the control group and the Shark liver oil treated group as the mean values were $(49.6 \pm 21.82)$ and $(69.4 \pm 25.27)$

There was also a significant increase in the total sperm abnormalities in the mean values of Taxotere treated group over the mean value of the control group and Shark liver oil only treated group where the mean values of them were $(972.2 \pm 38.48) v s(49.6 \pm 21.82)$ and $(69.4 \pm 25.27)$.

Using Shark liver oil as a treatment after Taxotere dose injection showing a significant decrease in total sperm abnormalities comparing with taxotere treated group with mean values were $(91.4 \pm 34.75)$ vs $(972.2 \pm 38.48)$. Also, the protective effect of Slo injection before Taxotere treatment showing a significant decrease in total sperm abnormalities comparing with the taxotere treated group as the mean values were $(384.8 \pm 49.71) v s \quad(972.2 \pm 38.48)$. And the injection of Taxotere with Slo also showing a significant decrease in total sperm abnormalities comparing with taxotere treated group as the mean

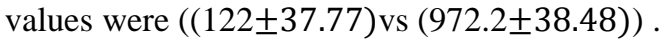

The results also show that using Slo as a treatment after Taxotere treatment was more efficient than its protective effect and than the injection of both SLO and Taxotere at the same time in decreasing the total sperm abnormalities.

The aim of this study evaluating the protective and treated effects of shark liver oil as natural products against the side effects of Taxotere on the chromosome, sperm. The results of our study showed that Taxotere as an anticancer drug causes cytogenetic effects including chromosome deletion, ring, centric attenuation, monosomy, and polyploidy. These results are consistent with as taxanes affect microtubules, it might be expected that they would induce numerical chromosome aberrations (aneuploidy) [15]. Docetaxel ( Taxotere) induced polyploid cells to undergo mitotic slippage and eventually spawn mononucleated cells via asymmetric cell division or neosis [16].

Table (2) The average structural and numerical chromosomal aberration in mice bone marrow cells.

\begin{tabular}{|c|c|c|c|c|c|c|}
\hline Groups & Deletion & $\begin{array}{l}\text { Centromeric } \\
\text { attenuation }\end{array}$ & Ring & Monosomy & Polyploidy & $\begin{array}{c}\text { Total } \\
\text { aberrations }\end{array}$ \\
\hline Control $^{\mathrm{a}}$ & $\operatorname{cdef}(1.2 \pm 0.58)$ & $(1.6 \pm 0.51) \mathrm{cdef}$ & $(0.4 \pm 0.24) \mathrm{ce}$ & $(1.8 \pm 0.37)$ cef & $(0 \pm 0)$ cef & $(5.4 \pm 2.1)$ \\
\hline $\mathrm{SLO}^{\mathrm{b}}$ & $(2.2 \pm 0.66) \mathrm{cdef}$ & $(2.8 \pm 0.37) \mathrm{cdef}$ & $(0.4 \pm 0.4)$ cef & $(1.6 \pm 0.68) \mathrm{cdef}$ & $(0 \pm 0)$ cef & $(7.8 \pm 2.31)$ \\
\hline Taxotere $^{c}$ & $(135 \pm 5.8)$ abdef & $(11 \pm 1.22)$ abdef & $(2.8 \pm 0.2)$ abdef & $(22.8 \pm 1.5)$ abdf & $(1.6 \pm 0.4) \mathrm{abd}$ & $(174.6 \pm 9.63)$ \\
\hline $\begin{array}{l}\text { Taxotere } \\
+ \text { SLO }^{\mathrm{d}}\end{array}$ & $(64.4 \pm 1.78)$ abcef & $(4.6 \pm 0.75)$ ace & $(1.2 \pm 0.37) \mathrm{d}$ & 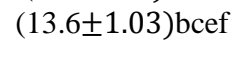 & $(0.4 \pm 0.24)$ ce & $(84.6 \pm 4.41)$ \\
\hline $\begin{array}{l}\text { SLO + } \\
\text { Taxotere }^{\text {e }}\end{array}$ & $(103.8 \pm 4.07) \mathrm{abcdf}$ & $\operatorname{abcd} 7.2 \pm 0.86)($ & $(1.8 \pm 0.37) a b c$ & $(21.2 \pm 1.07) a b d$ & $(1.4 \pm 0.24) \mathrm{abd}$ & $(136.4 \pm 6.61)$ \\
\hline $\begin{array}{l}\text { Taxotere } \\
\& \text { SLO }^{f}\end{array}$ & $(76 \pm 3.87)$ abcde & $(5.4 \pm 0.75)$ abcd & $(1.2 \pm 0.49) \mathrm{bc}$ & $(18.6 \pm 0.51)$ abcd & $(1 \pm 0.32) a b$ & $(102.6 \pm 6.18)$ \\
\hline
\end{tabular}

The significance was indicated as follows: a Significant with control; B significant with Slo; c Significant with Taxotere; D significant with (Taxotere+Slo); E significant with (Slo+Taxotere); $\mathrm{F}$ significant with (Taxotere\&Slo); significance means $\mathrm{p}<0.05$.

Docetaxel -resistant human breast cancer cell lines (MCF-7 and MDA-MB-231) were created, and comparative genomic hybridization was used to identify genomic regions associated with resistance to docetaxel. MCF-7 resistant cells showed amplification of chromosomes 7 , 17 and 18, and the deletion in chromosomes 6, 10, and 12. MDA-MB-231 resistant cells showed a gain of chromosomes 5, and 9, and loss of chromosomes 4, 8,10,11, 12and 18[17].
Also, Taxotere caused head abnormalities of mice sperms like without hook and hammer shape head and also caused tail abnormalities in sperm like a coiled tail. These results agree with who observed that Taxotere as a chemotherapeutic agent leads to damage in the reproductive system [18]. Reproductive organs, especially testes, are the target organs for the damage resulting from chemotherapeutic agents. The testis produces mature gametes through spermatogenesis which is negatively affected when exposed to chemotherapeutic agents. Also, it was found that Docetaxel severely repressed spermatogenesis and sperm motility, and dramatically increased sperm abnormality in mice[19]. 
Shark Liver Oil Protects the Chromosome and Sperm of Mice against the Cytotoxicity of Taxotere 104

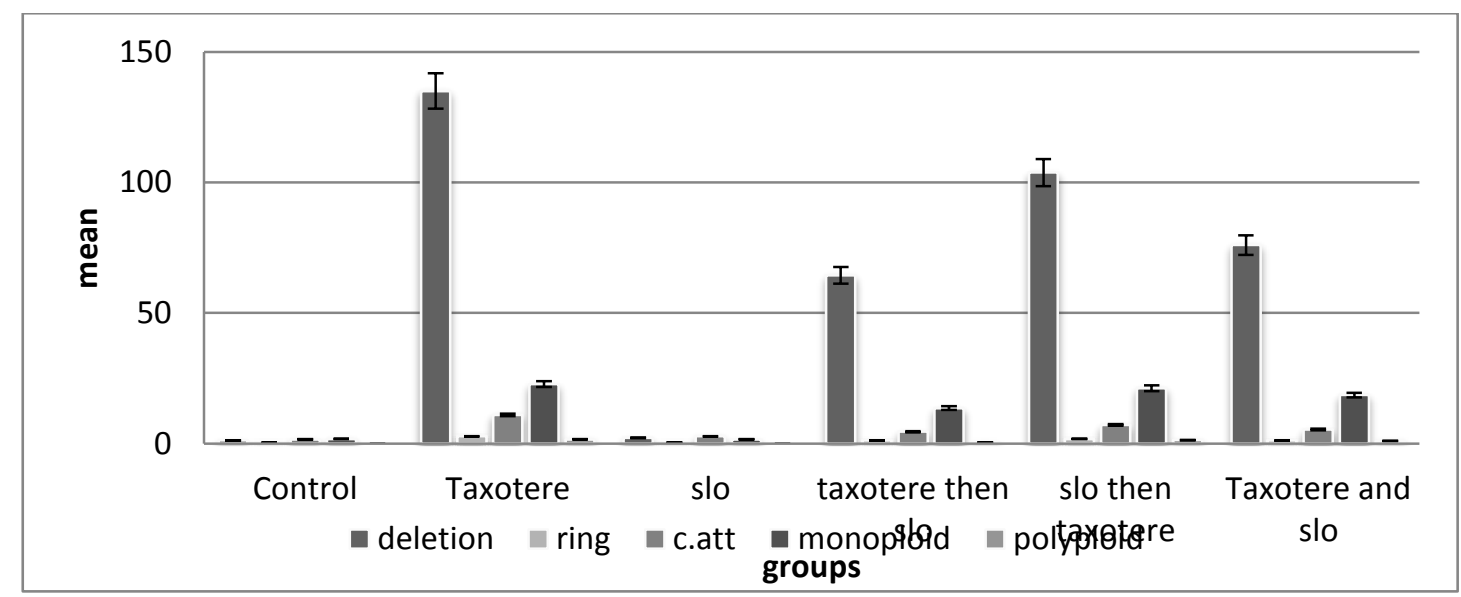

Fig (2) The average structural and numerical chromosomal aberration in mice bone marrow cells

Table (3) The average of the sperm head and tail abnormalities in male mice

\begin{tabular}{lccccc}
\hline Groups & Without hook & Amorphous & Hummer & Coiled & $\begin{array}{c}\text { Total } \\
\text { aberrations }\end{array}$ \\
\hline Control $^{\mathbf{a}}$ & $(3.2 \pm 1.28) \mathrm{cef}$ & $(19.4 \pm 8.6)$ & $(7 \pm 3.1) \mathrm{cef}$ & $(2.8 \pm 1.15) \mathrm{cdef}$ & $(49.6 \pm 21.82)$ \\
SLO $^{\mathbf{b}}$ & $(3.4 \pm 1.6) \mathrm{c}$ & $(24 \pm 10.7) \mathrm{c}$ & $(9.6 \pm 4.29) \mathrm{cf}$ & $(14.8 \pm 1.71) \mathrm{cdef}$ & $(40.4 \pm 17.619)$ \\
Taxotere $^{\mathbf{c}}$ & $(12.8 \pm 2.7) \mathrm{abd}$ & $(10.6 \pm 4.7) \mathrm{b}$ & $(19.2 \pm 8.58) \mathrm{ab}$ & $(907 \pm 12.4) \mathrm{abdef}$ & $(972.2 \pm 38.48)$ \\
Taxotere $^{\mathbf{d}}$ & $(6.6 \pm 2.29) \mathrm{c}$ & $(20 \pm 8.94)$ & $(12.8 \pm 5.72)$ & $(28.8 \pm 7.5) \mathrm{abce}$ & $(91.4 \pm 34.75)$ \\
SLO $^{\mathbf{S}}$ & & & & & \\
$\begin{array}{l}\text { Taxotere } \\
\text { e }\end{array}$ & $(13 \pm 3.86) \mathrm{ab}$ & $(21.4 \pm 9.5)$ & $(19.8 \pm 8.85)$ & $(304 \pm 15.7) \mathrm{abcdf}$ & $(384.8 \pm 49.71)$ \\
$\begin{array}{l}\text { Taxotere } \\
\text { \& SLO }\end{array}$ & $(14.2 \pm 2.5) \mathrm{ab}$ & $(18.2 \pm 8.13)$ & $(23.4 \pm 10.46)$ & $(42.6 \pm 6.18) \mathrm{abce}$ & $(122 \pm 37.77)$ \\
\hline
\end{tabular}

The significance was indicated as follows: a Significant with control; B significant with Slo; c Significant with Taxotere; D significant with

(Taxotere+Slo); E significant with (Slo+Taxotere); F significant with (Taxotere\&Slo); significance means $\mathrm{p}<0.05$.

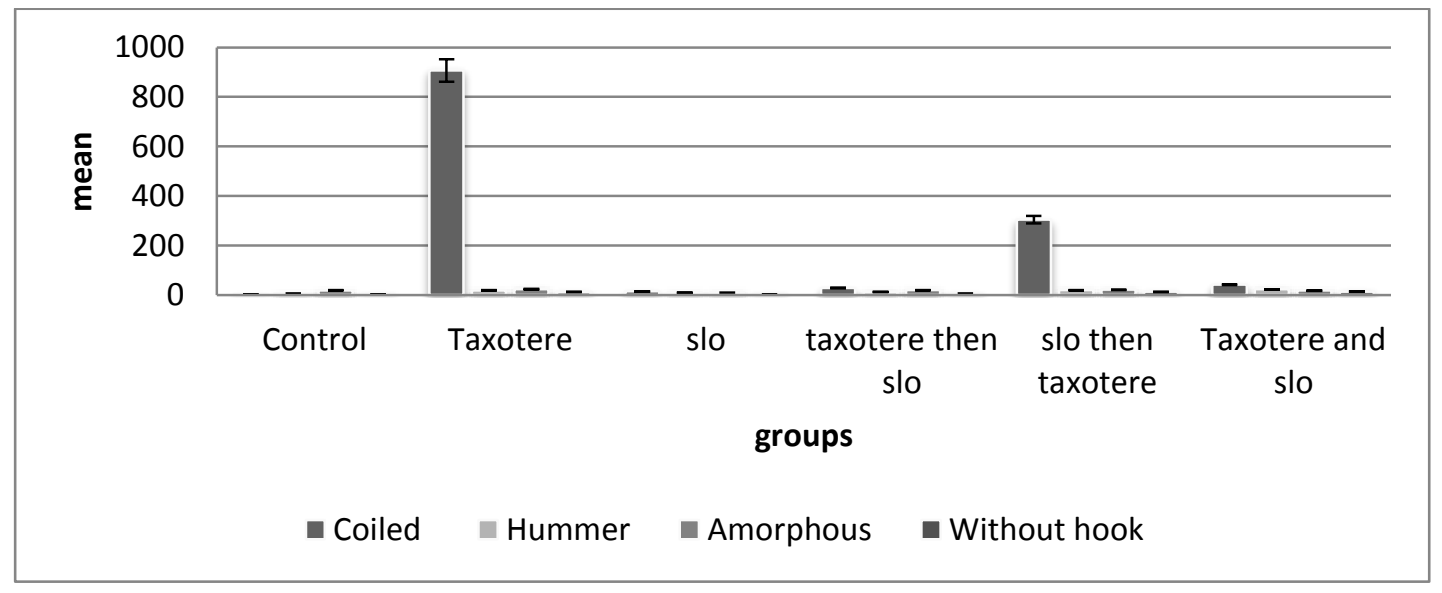

Fig (3) The average of the sperm head and tail abnormalities in male mice 
Both head and tail abnormalities were detected in 1000 sperm per mice. Table (3) and Fig (3) show these data. Head abnormalities include banana-shaped, without hook, amorphous and hummer head. The tail abnormalities include sperms with a coiled tail.

A)

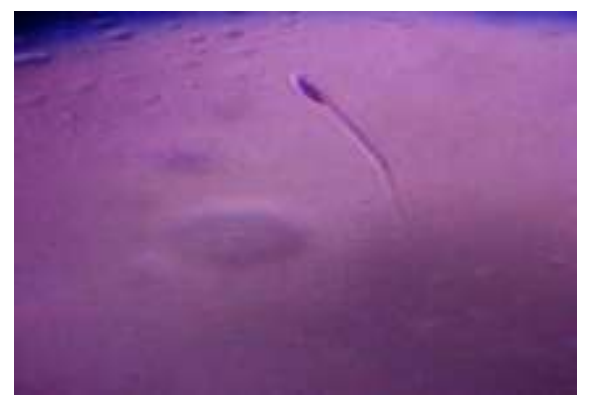

C)

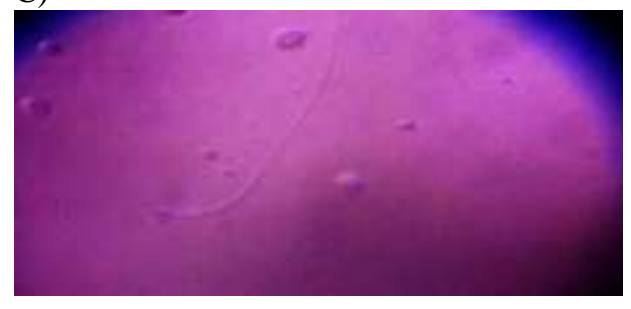

B)

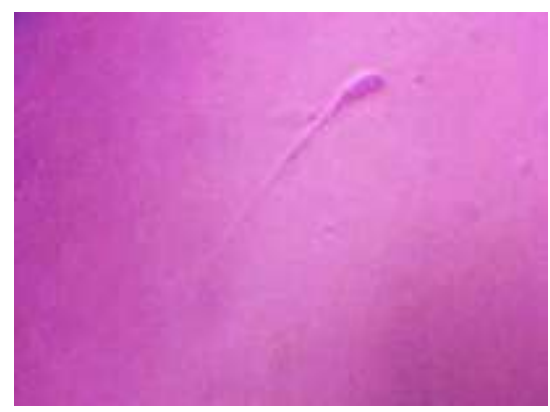

D)

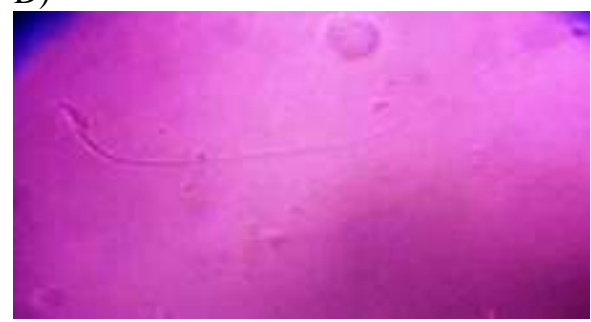

E)

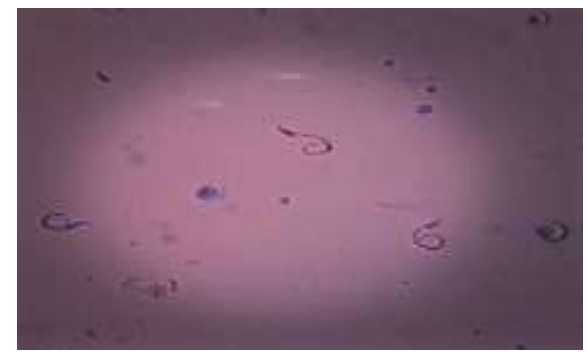

Fig(4) A) normal sperm. B) without a hook. C) Amorphous. D) Hummer. E) Coiled tail.

All our results showed how efficient the shark liver oil is acting as a treatment against the side effect of Taxotere. The natural ether-lipids 1-Oalkylglycerols from shark liver oil improve boar sperm motility and fertility. The natural etherlipids 1-O-alkylglycerols have multiple in vitro and in vivo properties: they reduce the side effects of radiotherapy, inhibit tumor growth and both stimulate and modulate immune responses[8]. Different mechanisms are suggested for these multiple activities, resulting from the incorporation of 1-O-alkylglycerols into membrane phospholipids, and lipid signaling interactions [9].

\section{Conclusion}

Taxotere causes structural and numerical chromosomal aberration as shown in results.
Deletion, centromeric attenuation, and ring, monoploidy and polyploid were detected. It also causes sperm's head abnormalities to include without hook, amorphous and hummer head. The sperm's tail abnormalities include sperms with coiled tails. It is so efficient to use shark liver oil as a treatment against the side effect of Taxotere.

\section{References}

[1] Sh. Noguchi, Predictive factors for response to docetaxel in human breast cancers, Cancer Science, vol 97, PP. 813820, 2006.

[2] K.A. Hotchkiss, A.W. Ashton, R. Mahmo od, R.G. Russell, J.A. Sparano and E.L. S chwartz,Inhibition of Endothelial Cell Function in Vitro and Angiogenesis in 
Vivo by Docetaxel ( Taxotere ): Association with Impaired Repositioning of the Microtubule Organizing Center, Mol Cancer Ther, vol 1, PP. 1191-1200, 2002.

[3] F. Iole and F. Iole, “Annex I," EU Neighb. Policy Maghreb, Vol.1, PP. 188-188, 2018.

[4] G. Hassett, P. Harnett, N. Manolios, Scleroderma in association with the use of docetaxel (taxotere) for breast cancer, Clinical and Experimental Rheumatology, Vol.19, PP.197-200, 2001.

[5] L. A. Kraus, S. K. Samuel, S. M. Schmid, D. J. Dykes, W. R. Waud and M. C. Bissery, The mechanism of action docetaxel (Taxotere $\left.{ }^{\circledR}\right)$ in xenograft models is not limited to bcl-2 phosphorylation. Investigational New Drugs, Vol. 21, PP. 259- 268, 2003.

[6] R. S. Herbst, and F. R. Khuri, Mode of action of docetaxel - A basis for combination with novel anticancer agents.Cancer Treatment Reviews, Vol. 29, PP. 407-415,2003.

[7] P. Gupta, K. Singhal, A. K. Jangra, V. Nautiyal, and A. Pandey, review article shark liver oil, Vol. 1,PP. 1-15, 2012.

[8] A. L. Deniau, P. Mosset, F.Pédrono, R. Mitre, D. Le Bot, and A. B. Legrand, Multiple beneficial health effects of natural alkylglycerols from shark liver oil. Marine Drugs, Vol. 8, PP.2175-2184, 2010.

[9] Y. Yonemura, Y. Endou, E. Bando, K. Kuno, T. Kawamura, M. Kimura, T. Shimadac, K. Miyamotoc, T. Sasakib, and P.H. Sugarbaker, Effect of intraperitoneal administration of docetaxel on peritoneal dissemination of gastric cancer. Cancer Letters, Vol 210, PP. 189-196, 2004.

[10] M. Hajimoradi, Z. Mohammad, A. Akbar, S. Daneshmandi and N. Pakravan, The effect of shark liver oil on the tumor infiltrating lymphocytes and cytokine pattern in mice, Journal of Ethnopharmacology, Vol. 126,PP.565570,2009 .

[11]M. E. M. Zowail, G.Y. Osman, A.H. Mohamed, and H. M. I. El-Esawy, Protective Role of Lactobacillus Sporogenes ( Probiotic ) on Chrom Osom
Al Ab Errat Ions and Dna Fr Agm Ent Ation in Schistosoma Mansoni Infected M Ice. The Egyptian Society of Experimental Biology, vol 8, PP. 121130,2012.

[12] A. Mukherjee, A. K. Giri, A. Sharma, and G. Talukder, Relative efficacy of shortterm tests in detecting genotoxic effects of cadmium chloride in mice in vivo. Mutation Research/Genetic Toxicology, vol 206, PP. 285-295, 1988.

[13]

B. S. Green, Understanding the One-Way Anova. Vol. 3, PP. 12, 2009.

[14] K. Mittal, S. Donthamsetty, R. Kaur, C. Yang and M. V. Gupta, Multinucleated polyploidy drives resistance to Docetaxel chemotherapy in prostate cancer. British journal of cancer, Vol. 116, PP. 1186$1194,2017$.

[15] S. L. Mcdonald, D. A. J. Stevenson, S. E. Moir, A. W. Hutcheon, N. E. Haites, S. D. Heys and A. C. Schofield, Genomic changes identified by comparative genomic hybridisation in docetaxelresistant breast cancer cell lines, European Journal of Cancer, Vol. 41, PP. 10861094,2005.

[16] S. Sariözkan, G. Türk, M. Güvenç, A. Yüce, F. Cantürk, and A. H. Yay, Effects of cinnamon ( C . zeylanicum ) bark oil against taxanes-induced damages in sperm quality, testicular and epididymaloxidant/antioxidant balance, testicular apoptosis, and sperm DNA integrity. Nutrition and Cancer, Vol. 68, PP. 481-494, 2016.

[17] L. Zhang, Y. Yang, Y. Song and H. Yang, Nanoparticle Delivery Systems Reduce the Reproductive Toxicity of Docetaxel in Rodents. Nano LIFE, Vol. 4, PP. 1-1, 2014.

[18] R. Mitre, C. Cheminade, P. Allaume, P. Legrand and A. B. Legrand, Oral intake of shark liver oil modifies lipid composition and improves motility and velocity of boar sperm. Theriogenology, Vol. 62, PP.1557-1566,2014.

[19] K.S. Cunha, Taxanes: the genetic toxicity of paclitaxel and docetaxel in somatic cells of Drosophila melanogaster.Mutagenesis, Vol.16, PP. 79-84, 2001. 